\title{
Marthin Rozo Castaño
}

* 1991 Bogotá, Colombia | Vienna, Austria

Marthin's work revolves around nature and its paradoxical relationship with mankind. For him, observation consists of recognising the rhythm of the existence of other beings. This is the first step in his process of artistic creation. His motivation resides in revealing natural events that go unnoticed. He wants to transmit scientific knowledge and his fascination for the living. To show other everyday life parallel to human's as a mirror to recognize their own.

\section{One Human Day}

16 prints and sound installation, 2018

One Human Day examines the potentiality of a path as scientific data and as drawing. Space becomes a determining factor of the resulting line taken by different beings. Confronting a varied range of these quotidian studies in one space invokes a kind of expanded vision of a personal and collective reality. The artwork comprises 16 different human day-to-day paths over the world. Each path corresponds with a one-minute sound landscape, recorded by each person who took part in the project. This enriches the experience when accompanying the line via the senses. The resulting image questions authorship. Drawn and traced by a human, drawn again by a printer machine and presented as a hybrid between data and drawing.
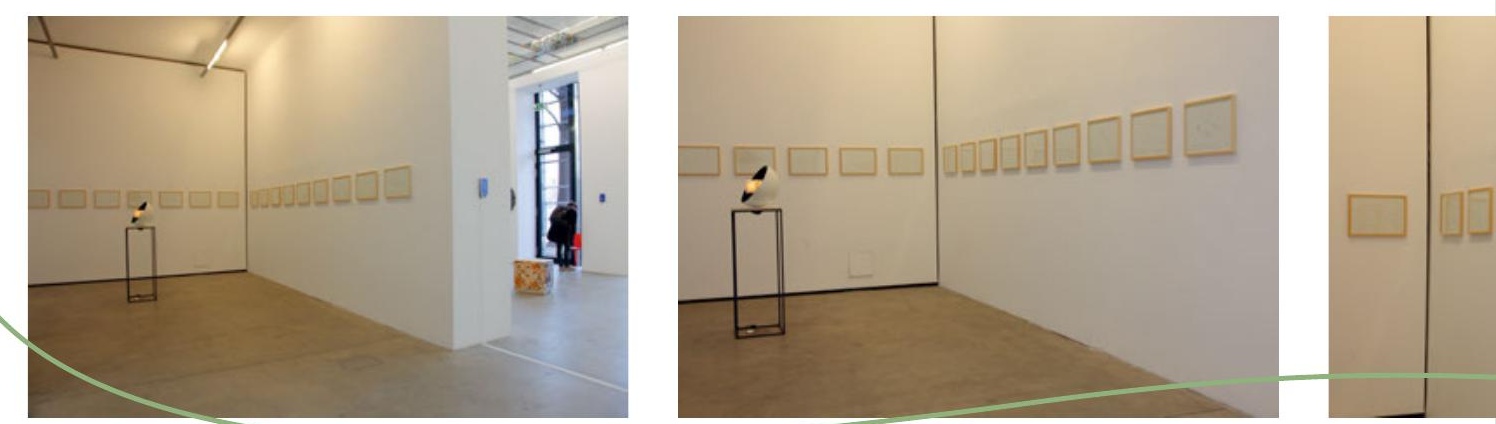


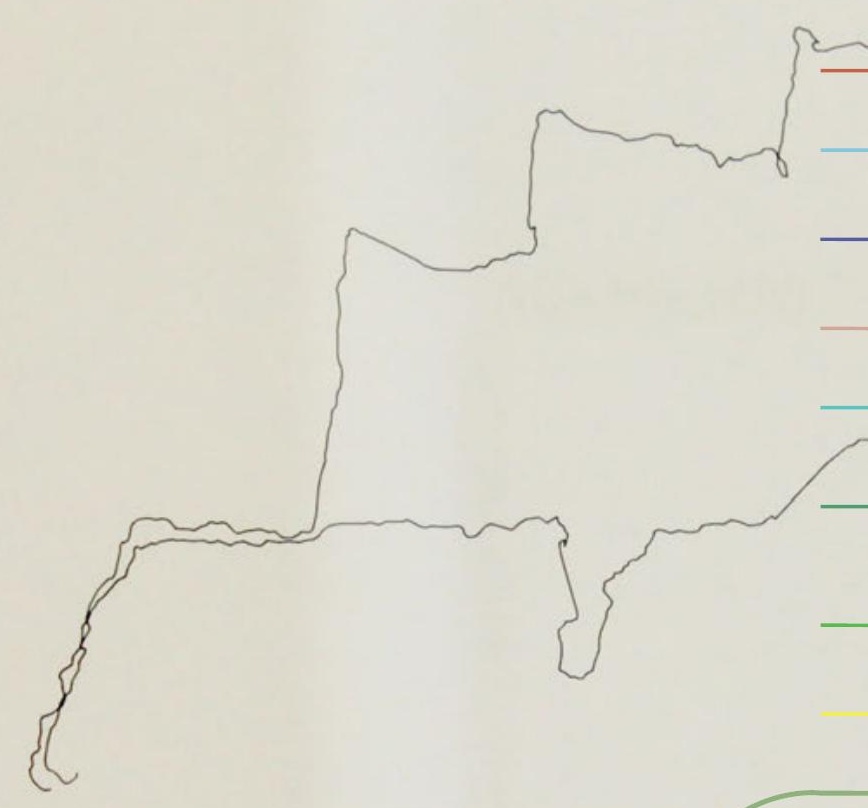

glangehme, China, 3.75 tem
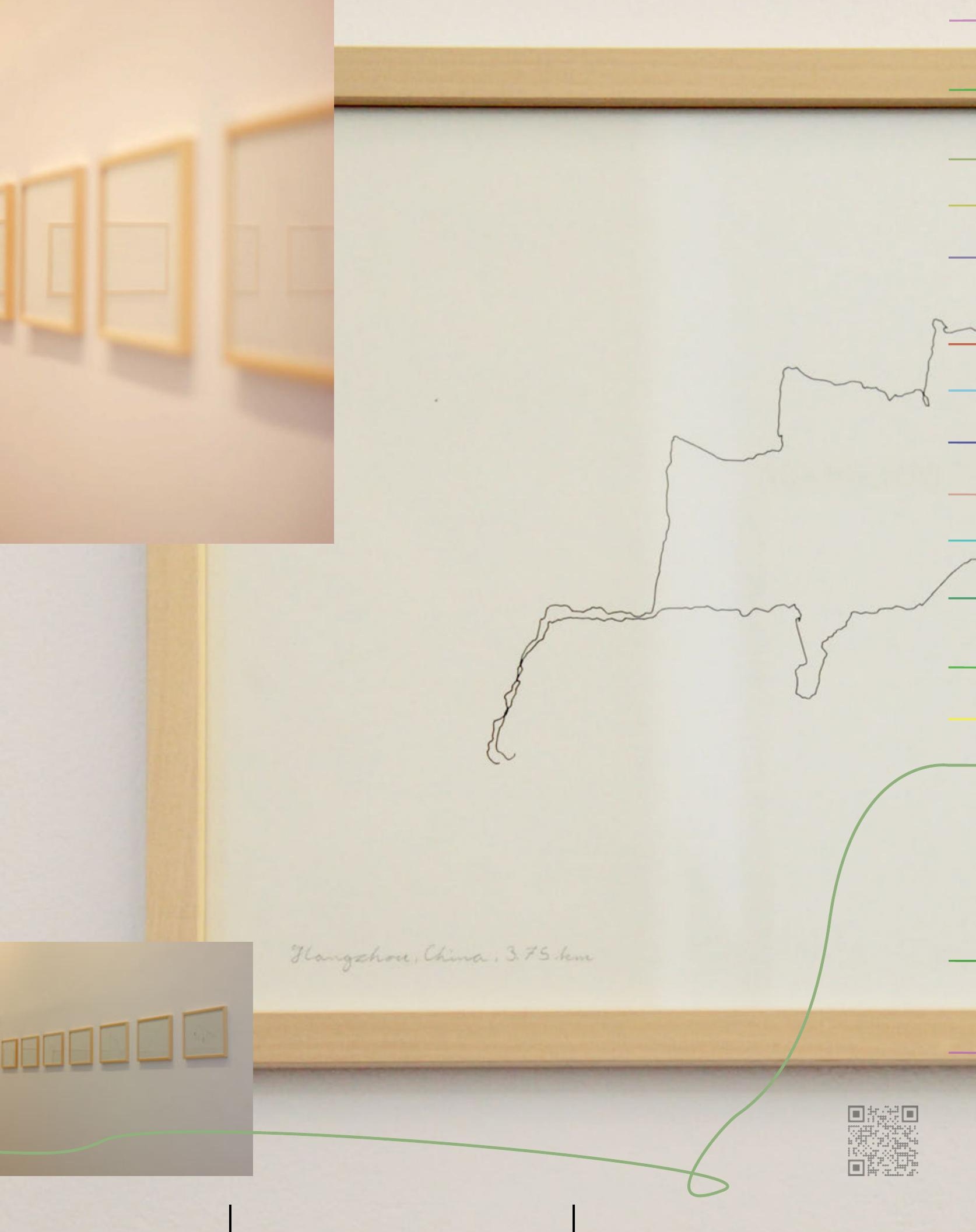

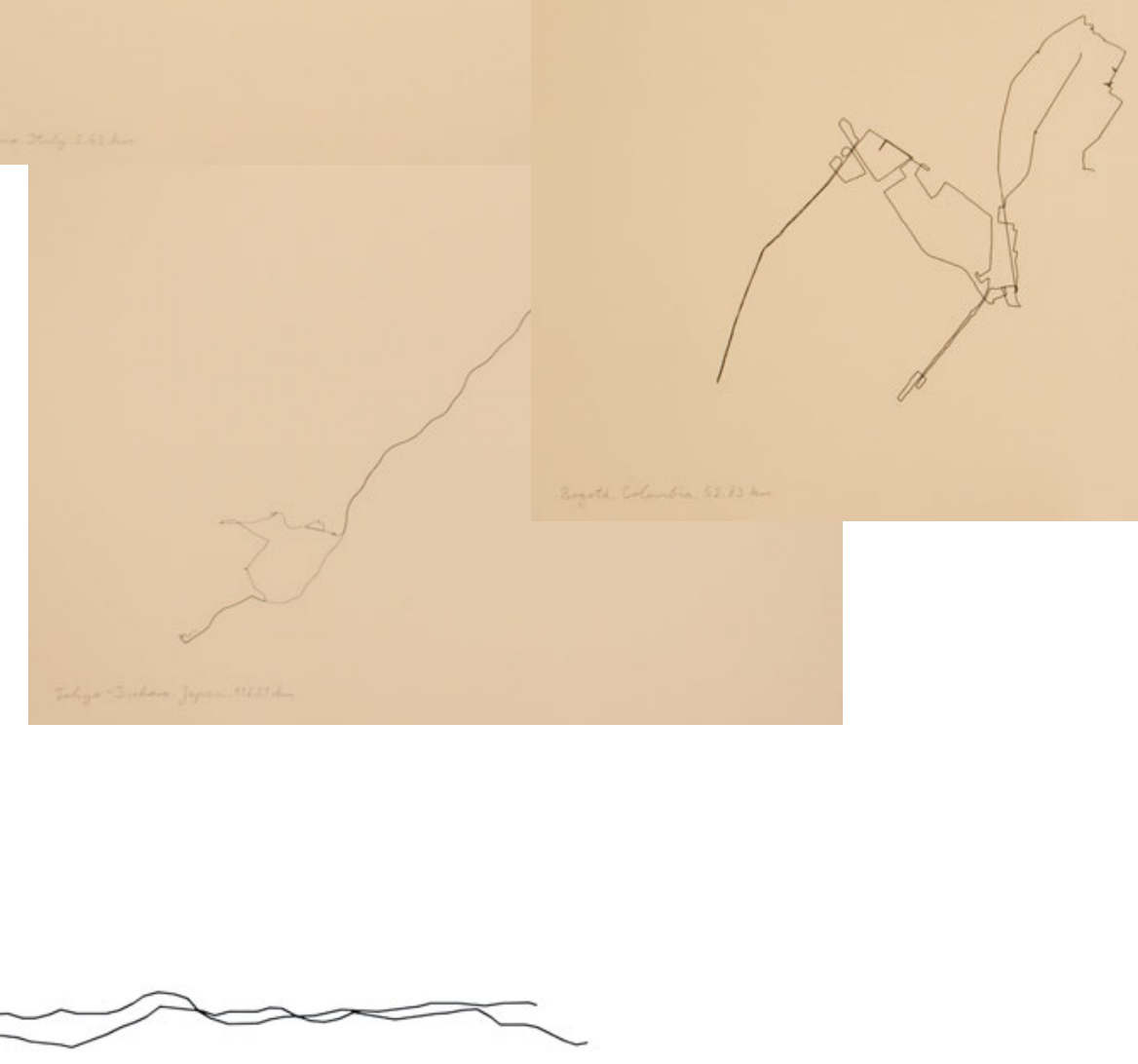


\section{Rebecca Fortnum}

Martin Reinhart

\section{Adelheig Heftberger}

\section{Virgil Widrich}

\section{Many Luksch}

\section{Publication Team}

Monica C.LoCascio

Dario Srbic - ManyLuksch

Matthias Strohmaier

\section{RIAT}

Marthin Rozo

Chantal Faust

Istem Özen

Henry Rogers

Mattia Paganelli 
Paolo Canepelle

\section{Maximilian Gallo}

Anna Nazo

\section{Alberto Condotta}

\section{Laura Stoll}

\section{Sophie-Carolin Wagner}

Juan Cruz

\section{Nora Lengyel}

